\title{
Particle size distribution of the radon progeny and ambient aerosols in the Underground Tourist Route "Liczyrzepa" Mine in Kowary Adit
}

\author{
Katarzyna Wołoszczuk ${ }^{1, *}$, Krystian Skubacz ${ }^{2}$ \\ ${ }^{1}$ CENTRAL LABORATORY FOR RADIOLOGICAL PROTECTION, Department of Individual \\ Monitoring and Calibration, Konwaliowa 7, PL03194 Warsaw, Poland, woloszczuk@clor.waw.pl \\ ${ }^{2}$ CENTRAL MINING INSTITUTE, Silesian Centre for Environmental Radioactivity (BCR), Plac \\ Gwarków 1, 40-166, Katowice, Poland, kskubacz@gig.eu
}

\begin{abstract}
Central Laboratory for Radiological Protection, in cooperation with Central Mining Institute performed measurements of radon concentration in air, potential alpha energy concentration (PAEC), particle size distribution of the radon progeny and ambient aerosols in the Underground Tourist- Educational Route "Liczyrzepa" Mine in Kowary Adit. A research study was developed to investigate the appropriate dose conversion factors for short-lived radon progeny. The particle size distribution of radon progeny was determined using Radon Progeny Particle Size Spectrometer (RPPSS). The device allows to receive the distribution of PAEC in the particle size range from $0.6 \mathrm{~nm}$ to $2494 \mathrm{~nm}$, based on their activity measured on 8 stages composed of impaction plates or diffusion screens. The measurements of the ambient airborne particle size distribution were performed in the range from a few nanometres to about 20 micrometres using Aerodynamic Particle Sizer (APS) spectrometer and the Scanning Mobility Particle Sizer Spectrometer (SMPS).
\end{abstract}

\section{Introduction}

\subsection{Radon and its progeny}

There are three natural radioactive series in the environment, in each there is an isotope of radium and its decay products radon $\left({ }^{222} \mathrm{Rn}\right)$, thoron $\left({ }^{220} \mathrm{Rn}\right)$ or actinon $\left({ }^{219} \mathrm{Rn}\right)$. Among them in the air dominates the first one, radioactive noble gas called radon, which is colourless, odourless and tasteless. The half-lifes of radon, thoron and action differ by four orders of magnitude. It is respectively: 3.8 days, $56 \mathrm{~s}$, and $4 \mathrm{~s}$. This is very important from the viewpoint of their distribution in the air and the development of hazards that are significant especially in places with relatively poor ventilation such as caves, underground mines and buildings. Taking into account the exposure due to by these isotopes, the most significant is usually radon, and less often thoron.

\footnotetext{
* Corresponding author: woloszczuk@clor.waw.pl
} 
Radon decay products, also called "radon progenies" are no longer gases but are solid particles. Radon decay products are divided into two groups: the "short-lived" radon daughters ${ }^{218} \mathrm{Po}(3.05 \mathrm{~min}),{ }^{214} \mathrm{~Pb}(26.8 \mathrm{~min}),{ }^{214} \mathrm{Bi}(19.7 \mathrm{~min})$, and ${ }^{214} \mathrm{Po}(164 \mu \mathrm{s})$ with half-lives below $30 \mathrm{~min}$; and the "long-lived" radon decay products ${ }^{210} \mathrm{~Pb}(22.3 \mathrm{a}),{ }^{210} \mathrm{Bi}$ $(5.01 \mathrm{~d})$, and ${ }^{210} \mathrm{Po}(138.4 \mathrm{~d})$ [1]. The prevalent contribution to the dose give short-lived progenies rather than radon itself.

After the formation from the radon isotope by decay, the freshly generated radionuclides react very fast $(<<1 \mathrm{~s})$ with trace gases and molecules of water vapor and become small particles, called clusters or unattached fraction with diameters from 0.5 to $5 \mathrm{~nm}$, composed primarily of the ${ }^{218} \mathrm{Po}$ [1]. The process was illustrated in Fig. 1. In aerosol-rich air dominates attached fraction- radioactive aerosols with diameter up to $1000 \mathrm{~nm}$ with predominant size between 50 and $500 \mathrm{~nm}$.

The dose due to radon progeny depends on the particle deposition and site of their deposition in the respiratory tract which is closely related to the particle size distribution, Deposition of aerosols in the respiratory tract depends mainly on their size, breathing way and ventilation rate, and is due to the forces of inertia, sedimentation and diffusion. At a higher ventilation rate via mouth, the aerosol deposition in the respiratory system is mainly connected to the inertia forces. This mechanism occurs particularly for particles with diameters greater than $4 \mu \mathrm{m}$. The role of sedimentation increases with a longer retention time of air in the respiratory system and for particles with diameters in the range of 0.1-4 $\mu \mathrm{m}$. The diffusion process prevails for particles with smaller size [2]. Very dangerous are so-called ultrafine particles with sizes below $100 \mathrm{~nm}$ and high diffusion coefficient because their dose conversion factors can be several dozen higher as compared to $100-500 \mathrm{~nm}$ particles. The high dose conversion factors also correspond to coarse particles close to size of $10 \mu \mathrm{m}$ but their concentration in the air is usually small.

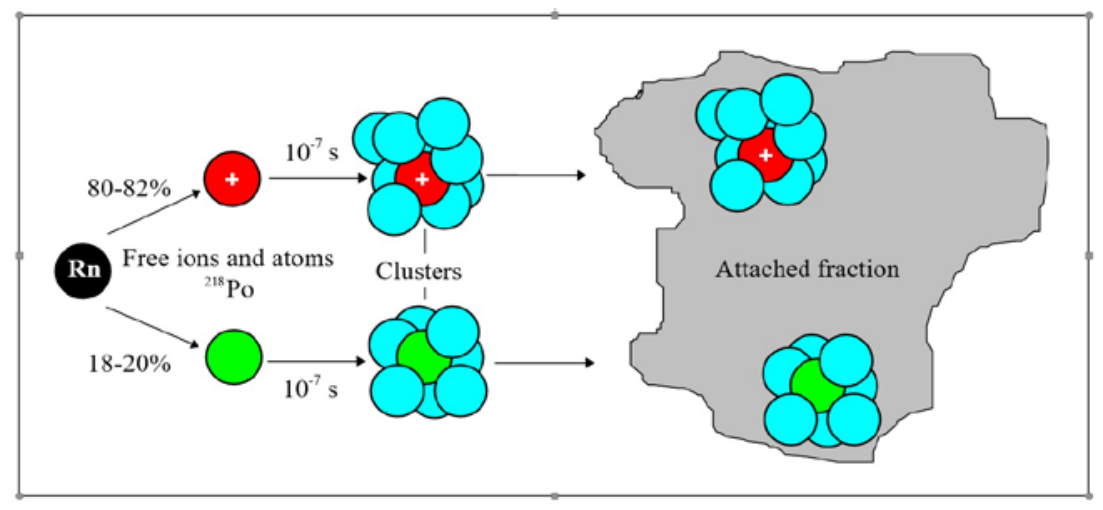

Fig. 1. Basic processes of radon decay product behaviour in air defining the concept of "unattached" and "attached" fractions [1]

It is estimated that equivalent dose to the lung from radon gas is only about one hundredth of that from its short-lived progeny which constitute the main health hazard to the human respiratory tract in the radon environment [3]. The annual effective dose, a measure of this hazard, is calculated as a product of the potential alpha energy concentration in the air (PAEC), exposition time ( $\mathrm{t}$ ), and a dose conversion factor (DCF).

$$
\mathrm{E}=(\mathrm{PAEC} \cdot \mathrm{t}) \cdot \mathrm{DCF}
$$

where: 
E - the annual effective dose [Sv/year],

PAEC - potential alpha energy concentration $\left[\mathrm{J} / \mathrm{m}^{3}\right]$

$\mathrm{t}$ - exposition time [h/year]

$\mathrm{DCF}$ - dose conversion factor $\left[\mathrm{Sv} /\left(\mathrm{J} \cdot \mathrm{h} / \mathrm{m}^{3}\right)\right]$

There are two approaches to the estimation of DCF- epidemiological and dosimetric. Epidemiological model introduces only two conversion factors, $1425 \mathrm{mSv} /\left(\mathrm{J} \cdot \mathrm{h} / \mathrm{m}^{3}\right)$ for the occupational hazard and $1100 \mathrm{mSv} /\left(\mathrm{J} \cdot \mathrm{h} / \mathrm{m}^{3}\right)$ for the general population. The conversion factors are determined from the epidemiological studies of uranium miners. The second uses the biokinetic and dosimetric models developed by the International Commission on Radiological Protection (ICRP). This model is used to determine the deposition of inhaled radionuclides in the various regions of the respiratory system as a function of inhaled particle size [4].

\subsection{Study site}

Measurements were conducted in the Underground Tourist- Educational Route 'Liczyrzepa' Mine in Kowary Adit (Fig.2). These are the remnants after exploitation of iron ore and uranium. From 1947 to 1957, the mine was involved in uranium extraction and it operated as a subsidiary of Industrial Plants R-1, otherwise known as National Detached Company. More than 20 tunnels were dug during those times. The mine is today converted into a tourist attraction. The long tour through one of the underground workings is a sort of multimedia museum with exhibitions of the mining history [5].

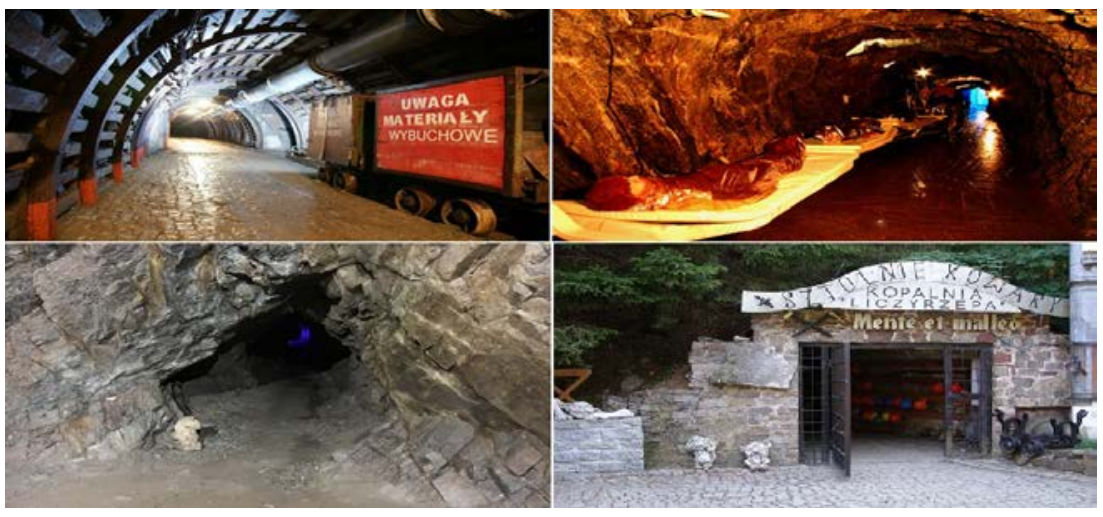

Fig. 2. Underground Tourist- Educational Route 'Liczyrzepa' Mine in Kowary Adit [5]

\section{Measurement methods}

\subsection{RPPSS}

Central Laboratory for Radiological Protection is equipped with the Radon Progeny Particle Size Spectrometer (RPPSS) that is able to determine effective dose related to radon progeny according to the dosimetric model recommended by International Commission on Radiological Protection (ICRP) [4], taking into account the size distribution of particles compound of these progeny and ambient aerosols. This device was constructed and manufactured in the Australian Radiation Protection and Nuclear Safety Agency (ARPANSA). It allows to measure the progeny activities in 8 stages that correspond to 
particle size in the range from $0.6 \mathrm{~nm}$ to $2494 \mathrm{~nm}$. Then the activity size distribution and a size-weighted dose conversion factors for breathing rates related to both occupational and environmental exposures are calculated by fitting of the experimental data to an analytical function.

RPPSS is designed to work in two modes- grab and continuous sampling mode. In continuous mode the RPPSS as a portable device analyzes potential alpha energy concentration on each stage of the sampling head, and finally the activity-size distributions and weighted dose conversion factors are derived from these results. Grabbing mode is used with the Canberra 8224 Analog Multiplexer (AMX) and Accuspec MCA to provide simultaneous 8-channel alpha spectroscopy. This allows to provide the activity size distributions individually for each radionuclide.

RPPSS comprises 8 stages operated in parallel: one open face stage, 4-stage diffusion battery system and 3-stage inertial impactor system. The eight sampling heads are counting simultaneous while the pump is sampling. The derived PAEC values for each stage are used as input for two independent deconvolution algorithms - Twomey [6] and Expectation Maximisation [7] to derive the particle size distributions. The software also includes radon progeny dose conversion factors for the ICRP Respiratory Track Model as implemented in the computer code RADEP (RAdon Dose Evaluation Program).

\subsection{APS and SMPS spectrometers}

Two particle spectrometers were applied to measure particle concentrations. The Aerodynamic Particle Sizer (APS spectrometer), made by TSI, USA (Fig. 3), was used to measure the concentration of particles that have aerodynamic diameters in the range from about $0.5 \mu \mathrm{m}$ to $20 \mu \mathrm{m}$. The entire range of measurement is divided into 52 channels, and evaluation of particle size relies on measuring particle flight time using two laser beams and comparing the indications with the calibration curve.

To test the finer particle size distribution, the Scanning Mobility Particle Sizer (SMPS spectrometer), also made by TSI, USA, was applied, comprising an EC-3080 Electrostatic Classifier (EC), DMA-3081 or DMA-3085 Differential Mobility Analyzer (Long DMA or Nano DMA) and CPC-3785 Condensation Particle Counter (CPC). At the air inlet to the electrostatic classifier, an impactor with a diameter of $0.0508 \mathrm{~cm}$ was mounted and the sample air passed through the spectrometer at a flow rate of $0.6 \mathrm{dm}^{3} / \mathrm{min}$ (Nano DMA) or $0.3 \mathrm{dm}^{3} /$ min (Long DMA). The adoption of such parameters allowed the detection of particles with sizes ranging from 4-106 nm using the Nano DMA or 15-698 nm with the Long DMA. The aerosol concentration, measured by the SMPS spectrometer, is a function of the mobility diameters, while, in the case of the APS spectrometer, of the aerodynamic diameters. The aerodynamic diameter that corresponds to an ambient particle is defined as a diameter of a sphere particle having the unit density of $1 \mathrm{~g} / \mathrm{cm}^{3}$ and the same settling velocity as the particle. The following nonlinear relationship between these two diameter types was applied [8] to compare distributions, measured by both spectrometers, and integrate the results:

$$
d_{\mathrm{p}}=d_{\mathrm{a}}\left(\frac{C_{\mathrm{C}}\left(d_{\mathrm{a}}\right)}{C_{\mathrm{C}}\left(d_{\mathrm{p}}\right)}\right)^{1 / 2}\left(\frac{\chi \rho_{\mathrm{o}}}{\rho_{\mathrm{p}}}\right)^{1 / 2} \quad C_{\mathrm{C}}(d)=1+\frac{\lambda}{d}\left(2.34+1.05 \mathrm{e}^{-0.39 \frac{d}{\lambda}}\right) \quad d=d_{\mathrm{a}} \text { or } d=d_{\mathrm{p}}
$$

where $d_{\mathrm{a}}$ is the aerodynamic diameter, $d_{\mathrm{p}}$ and $\rho_{\mathrm{p}}$ the diameter and density of the particles, respectively, $\chi$ the aerodynamic shape factor, $C_{\mathrm{c}}$ is so-called slip correction factor, $\rho_{\mathrm{o}}$ unit density of $1 \mathrm{~g} / \mathrm{cm}^{3}$, and $\lambda$ the mean free path of the gas molecules. The dimensionless 
aerodynamic shape factor $\chi$ is a correction factor to take into account the influence of the shape on particle motion according to Stokes's law.

\section{Measurements results}

During measurements of radon concentration in air, potential alpha energy concentration (PAEC), particle size distribution of the radon progeny and ambient aerosols were determined. These results are presented in Table 1-3 and in Fig. 3-6. The parameters allowed to determine the dose conversion factor $(\mathrm{DCF})$, and equilibrium factor $(\mathrm{F})$.

The measured concentrations of PAEC are high, especially compared to $0.05 \mu \mathrm{J} / \mathrm{m}^{3}$, which is not normally exceeded in open air $[9,10]$. For occupational exposure, taking into account the annual working time of 1800 hours and the dose conversion factor indicated in the legislation, the doses clearly exceed $6 \mathrm{mSv}$, i.e. the limit for exposure category A. However it is not greater than the boundary exposure limit.

The concentrations of environmental aerosols are significantly lower than in an active coal mine, where their concentration can reach $140 \cdot 10^{9}$ particles $/ \mathrm{m}^{3}$ [11]. The ultrafine particles with diameter up to $100 \mathrm{~nm}$ predominate in the distribution (table 2) predominate, and the contribution of coarse particles larger than $2.5 \mu \mathrm{m}$ does not exceed $0.1 \%$ in total concentration. However, they cannot be omitted taking into account the total particle surface area where their share is about $20 \%$.

Table 1. Measurements results

\begin{tabular}{|c|c|c|c|c|c|}
\hline $\begin{array}{c}\text { Measurement } \\
\text { day }\end{array}$ & $\begin{array}{c}\text { Radon } \\
\text { concentration in air } \\
{\left[\mathrm{Bq} / \mathrm{m}^{3}\right]}\end{array}$ & $\begin{array}{c}\text { Potential alpha } \\
\text { energy } \\
\text { concentration } \\
{\left[\mu \mathrm{J} / \mathrm{m}^{3}\right]}\end{array}$ & Humidity & Temperature & $\begin{array}{c}\text { Air } \\
\text { pressure } \\
{[\%]}\end{array}$ \\
\hline $1^{\text {st }}$ day & 1054 & 3.56 & 95 & 8.3 & 942 \\
\hline $2^{\text {nd }}$ day & 1081 & 4.82 & 82 & 9.5 & 944 \\
\hline
\end{tabular}

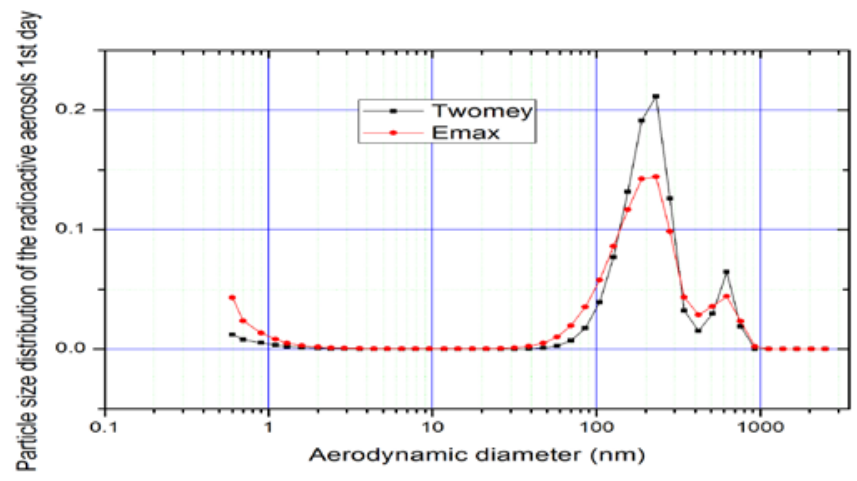

Fig. 3 Particle size distribution of the radon progeny $\left(1^{\text {st }}\right.$ day $)$ 


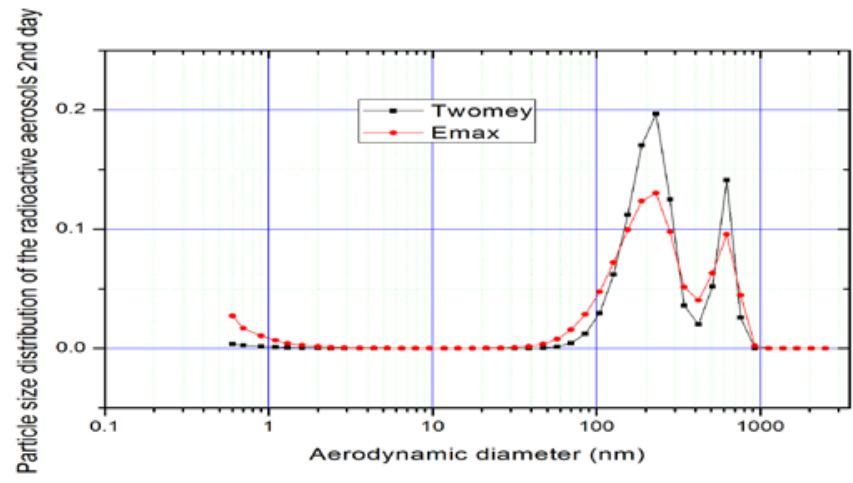

Fig. 4 Particle size distribution of the radon progeny $\left(2^{\text {nd }}\right.$ day)

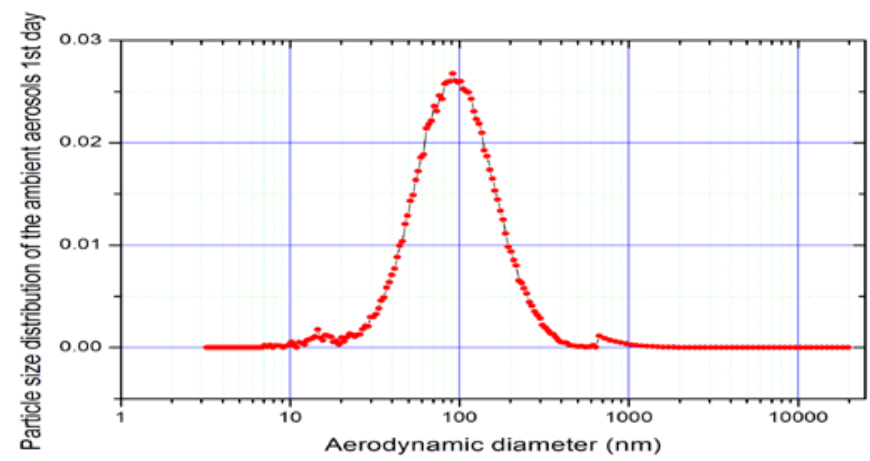

Fig. 5 Particle size distribution of the ambient aerosols ( $1^{\text {st }}$ day)

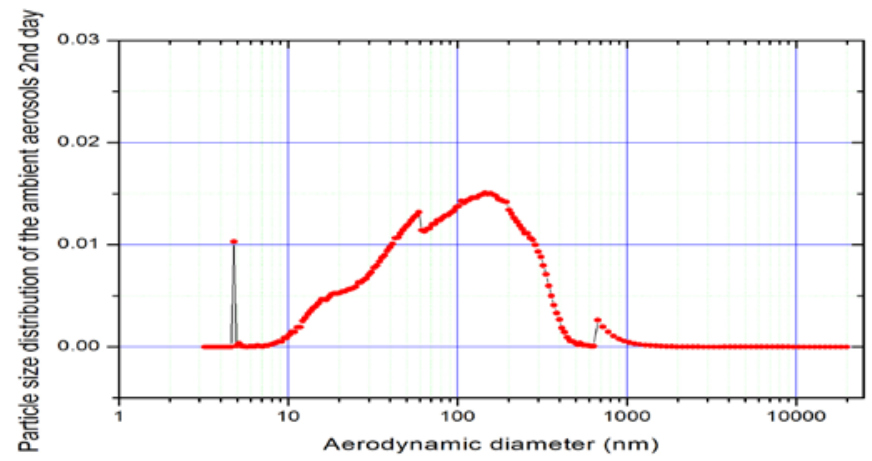

Fig. 6 Particle size distribution of the ambient aerosols ( $2^{\text {nd }}$ day) 
Table 2. Average total concentration of particles and their number contribution to the specific class of aerosol particles.

\begin{tabular}{|c|c|c|c|c|}
\hline \multirow{2}{*}{ Measurement day } & \multirow{2}{*}{$\begin{array}{c}\text { Total } \\
\text { concentration } \\
{\left[\text { particles } / \mathrm{m}^{3}\right]}\end{array}$} & \multicolumn{3}{|c|}{ Class of aerosol particles $[\mu \mathrm{m}]$} \\
\cline { 3 - 5 } & & LB-0.1 & $0.1-2.5$ & $2.5-10.0$ \\
\cline { 3 - 5 } & $2.7 \cdot 10^{9}$ & 73 & 27 & $<0.1$ \\
\hline $1^{\text {st }}$ day & $4.0 \cdot 10^{9}$ & 53 & 47 & $<0.1$ \\
\hline $1^{\text {st }}$ day & &
\end{tabular}

Table 3. Average total concentration of particles and their surface area contribution to the specific class of aerosol particles.

\begin{tabular}{|c|c|c|c|c|}
\hline \multirow{2}{*}{ Measurement day } & \multirow{2}{*}{$\begin{array}{c}\text { Total } \\
\text { concentration } \\
{\left[\text { particles } / \mathrm{m}^{3}\right]}\end{array}$} & \multicolumn{3}{|c|}{ Class of aerosol particles $[\mu \mathrm{m}]$} \\
\cline { 3 - 5 } & LB-0.1 & $0.1-2.5$ & $2.5-10.0$ \\
\cline { 3 - 5 } & $2.7 \cdot 10^{9}$ & 18 & 62 & {$[\%]$} \\
\hline $1^{\text {st }}$ day & $4.0 \cdot 10^{9}$ & 4 & 78 & 18 \\
\hline $1^{\text {st }}$ day & &
\end{tabular}

Based on measurements results dose conversion factors (DCF) for the occupational hazard (DCF OCC), for the general population (DCV Env) and equilibrium factor (F) were determined (Table 4). DCF values were also calculated based on the measurement results related to size distribution of ambient aerosols taking into account the method described in the publication [10]. The calculated coefficients differ significantly, although the trend is similar, and on the second measurement day they were higher in each case than these obtained in the first measurement day. There should be emphasized, however, that the DCF coefficients for RPPSS results were calculated for the range up to $2.5 \mu \mathrm{m}$, while the measuring range of SMPS + APS equipment also included particles larger than $2.5 \mu \mathrm{m}$. For such particles, the surface area that increases the possibility to catch the radon progeny is significant (Table 3), and the DCF values for such particles are significantly higher than for the size of $100-500 \mathrm{~nm}$.

Table 4. Measurements results

\begin{tabular}{|c|c|c|c|c|}
\hline Day of measurement & Method & $\begin{array}{c}\text { DCF Occ } \\
{\left[\mathrm{Sv} /\left(\mathrm{J} \cdot \mathrm{h} / \mathrm{m}^{3}\right)\right]}\end{array}$ & $\begin{array}{c}\text { DCF Env } \\
{\left[\mathrm{Sv} /\left(\mathrm{J} \cdot \mathrm{h} / \mathrm{m}^{3}\right)\right]}\end{array}$ & $\begin{array}{c}\mathrm{F} \\
{[\%]}\end{array}$ \\
\hline $1^{\text {st }}$ day & \multirow{2}{*}{ RPPSS } & 1.50 & 0.82 & 60 \\
\hline $2^{\text {nd }}$ day & & 1.14 & 0.78 & 80 \\
\hline $1^{\text {st }}$ day & \multirow{2}{*}{ SMPS+APS } & 4.11 & 3.34 & - \\
\hline $2^{\text {nd }}$ day & & 3.92 & 2.94 & - \\
\hline
\end{tabular}

\section{Conclusions}

Obtained particle size distribution of radon progeny shows three main peaks with the values about $1 \mathrm{~nm}, 180 \mathrm{~nm}$ and $570 \mathrm{~nm}$. The first peak corresponds to the unattached 
fraction which in this case was about $10 \%$. Second peak corresponds to the dominating ambient fraction in the distribution (Fig. 3-4), third peak correspond to the biggest particles.

Based on particle size distribution of radon progeny DCF were determined. In this case obtained values DCF are similar to values defined in Polish Atomic Law which are $1.4 \mathrm{~Sv} /\left(\mathrm{J} \cdot \mathrm{h} / \mathrm{m}^{3}\right)$ and $1.1 \mathrm{~Sv} /\left(\mathrm{J} \cdot \mathrm{h} / \mathrm{m}^{3}\right)$ respectively for the occupational hazard (DCF OCC), for the general population (DCV Env). However, the DCF values, calculated based on the measurement results related to size distribution of ambient aerosols were much higher, despite the both size distributions in the common range were nearly the same. That difference was caused probably by analyzing different size range related for RPPSS results and results related to the SMPS and APS spectrometers that also included particles larger than $2.5 \mu \mathrm{m}$.

\section{References}

1. J. Porstendörfer, Properties and behavior of radon and thoron and their decay products in the air. J. Aerosol Sci. 25 (1994)

2. K. Willeke, Generation of aerosols and facilities for exposure experiments, inhalation of aerosols: particle deposition and retention. Ann Arbor Science Publishers Inc. (1980)

3. Measurement and calculation of radon releases from NORM residues. - Vienna: International Atomic Energy Agency, Technical Reports Series No.474 (2013)

4. Human Respiratory Tract Model for Radiological Protection. ICRP Publication 66. Ann. ICRP 24, (1994)

5. http://www.jeleniastruga.pl

6. S. Twomey, Comparison of constrained linear inversion and iterative algorithm applied to the indirect estimation of the particle size distribution. J Comput Phys $\mathbf{1 8}$ (1975)

7. E.F. Maher, N. Laird, Algorithm reconstruction of particle size distributions from diffusion battery data. J Aerosol Sci 16 (1985)

8. C.W. Hinds, Aerosol technology, properties, behaviour, and measurement of airborne particles: 2nd ed. New York: John Wiley \& Sons, Inc; (1999)

9. S.A. Durrani, R. Ilić, Radon measurements by etched track detectors: applications in radiation protection, earth sciences and the environment. World Scientific Publishing Co. Pte. Ltd, (1997)

10. J. Porstendörfer, C. Zock, J. Wendt, A. Reineking, Radon parameters in outdoor air. International symposium on technologically enhanced natural radiation, Rio de Janeiro, (1999)

11. K. Skubacz, Ł. Wojtecki, P. Urban, The influence of particle size distribution on dose conversion factors for radon progeny in the underground excavations of hard coal mine. Journal of Environmental Radioactivity, DOI 10.1016/j.jenvrad.2016.05.020 (2016) 